\title{
APROXIMAÇÕES ENTRE CIÊNCIA E HISTÓRIAS AFRICANAS NA CONTAÇẪO DE HISTÓRIAS: UM RELATO DE EXPERIÊNCIA
}

\section{APPROXIMATIONS BETWEEN SCIENCE AND AFRICAN STORI- ES IN THE STORYTELLING: AN EXPERIENCE REPORT}

\author{
DOI: http://dx.doi.org/10.5965/1984317815032019034 \\ Valéria da Silva Lima \\ Instituto Federal do Rio de Janeiro \\ valeriaslima8910@yahoo.com.br \\ Neide Andrade Almeida \\ Universidade Federal do Estado do Rio de Janeiro \\ mneideandrade@gmail.com \\ Maylta Brandão dos Anjos \\ Instituto Federal do Rio de Janeiro \\ maylta@yahoo.com.br
}

\begin{abstract}
RESUMO
Este trabalho objetiva relatar uma experiência que aproxima as histórias africanas, afro-brasileiras e ciência com práticas de Contação de Histórias, envolvendo o que consideramos ser interdisciplinar. Tal fato, surge a partir de uma disciplina ministrada entre junho a agosto de 2017, num curso de Formação Inicial e Continuada ocorrido no Instituto Federal de Educação, Ciência e Tecnologia do Rio de Janeiro, campus avançado de Mesquita, com proposta de ensino verticalizado de politécnico. Questões de africanidade foram o foco de nossas ações, confirmando assim, num universo diverso, a luta por uma educação laica, democrática, inclusiva e de qualidade. As leis 10.639/03 e 11.645/08 formaram nosso arcabouço teórico. Os autores Celso Sisto, Fanny Abramovick, llan Bremanm e Attico Chassot do ensino de ciências nos auxiliaram com aproximações interdisciplinares nas contações de histórias. Diante disso, no contexto do curso, compartilhamos conhecimentos e algumas histórias da África e dos afro-brasileiros para que algumas histórias fossem conhecidas para desmistificação de estereótipos construídos socialmente. Propomos, junto aos alunos, uma metodologia participativa contando com a efetivação de uma prática contextual de sala de aula que integrasse saberes, rompesse preconceitos e desmistificasse os fenômenos naturais e o sentido da ciência. Fortalecendo, assim, conceitos e histórias que nos apresenta em universos amplos, distintos e integrados.
\end{abstract}

Palavras-chave: Contação de histórias. Africanidades. Literatura. Ensino de Ciências.

\section{ABSTRACT}

This work aims to report an experience that brings the African stories, afro-brazilian and science with practice of storytelling, involving what we consider to be the interdisciplinary. This fact emerges from a discipline administered between June and August 2017, a course of initial and continuing training occurred at the Federal Institute of Education, Science and Technology of Rio de Janeiro, advanced campus of Mosque, with a proposal for a verticalized of education polytechnic institute. Peoples issues were the focus of our actions, thus confirming, in a different universe, the fight for an education, secular, democratic, inclusive and quality. The Laws 10.639/03 and 11.645/08 formed our theoretical framework. The authors Celso Sisto, Fanny Abramovick, Ilan Bremanm and Attico Chassot of science teaching in helped with interdisciplinary approaches in the contações stories. In addition, in the context of the 
course, share knowledge and some stories from Africa and the Afro Brazilians to some stories were known to demystifying stereotypes socially constructed. We propose, together with the students, a participative methodology with the effectuation of a contextual practice of classroom that integrates knowledge, rupture prejudices and desmistificasse natural phenomena and the sense of science. Strengthening, thus, concepts and stories that introduces us into large universes, distinct and integrated

Keywords: Visual arts. Visually impaired. Synesthesia. Didactic-pedagogical method, Tactile planks.

\section{INTRODUÇÃO}

As histórias são construções humanas que perpassam gerações, seja para transmissão de conhecimento, saberes do senso comum, saberes políticos, econômicos, sociais e culturais, bem como saberes que se estabelecem para maior compreensão e apreensão dos fenômenos naturais.

Grupos humanos, em diversas localidades, sempre comunicavam por meio das histórias, pois elas estão presentes nas relações humanas, desde as mais simples às mais complexas, por isso deve ser estuda e preservada no sentido do alargamento das relações e compreensão do universo.

Em tempos primitivos, grupos humanos contavam suas histórias oralmente, ensinando as gerações mais jovens o caminho a ser seguido, explicando a natureza e suas manifestações. Com o advento da cultura escrita, os rituais de enunciações orais, cederam espaço para a relação individualizada entre leitor e texto, sobrepondo as produções escritas sobre a oralidade, valorizando grupos que utilizavam a cultura escrita, deixando em segundo plano, as comunidades orais.

Quando falamos de tradição em relação à história africana, referimo-nos à tradição oral, e nenhuma tentativa de penetrar a história e o espírito dos povos africanos terá validade a menos que se apóie nessa herança de conhecimentos de toda espécie, pacientemente transmitidos de boca a ouvido, de mestre a discípulo, ao longo dos séculos. Essa herança ainda não se perdeu e reside na memória da última geração de grandes depositários, de quem se pode dizer são a memória viva da África. (HAMPÂTÉ, 1977.pg 1) 
De boca a boca, de ouvido a ouvido, as histórias africanas chegaram até nós, visto ser a oralidade essencial para a existência humana, para manutenção e fortalecimento da cultura. Diante do contexto atual de sombras e mascaramento das identidades diversas, buscamos nas contações de histórias, aproximações com a tradição oral africana, visto que:

\begin{abstract}
É, pois, nas sociedades orais que não apenas a função da memória é mais desenvolvida, mas também a ligação entre o homem e a Palavra é mais forte. Lá onde não existe a escrita, o homem está ligado à palavra que profere. Está comprometido por ela. Ele é a palavra, e a palavra encerra um testemunho daquilo que ele é. A própria coesão da sociedade repousa no valor e no respeito pela palavra. Em compensação, ao mesmo tempo que se difunde, vemos que a escrita pouco a pouco vai substituindo a palavra falada, tornando-se a única prova e o único recurso;[...] .( HAMPÂTÉ, 1977.pg 2)
\end{abstract}

Sendo a memória um elemento de conhecimento cultural e interação com as gerações mais jovens, o resgate das contações de histórias é um movimento de observarmos atentos, o perigo de se contar uma única história num país marcado pela diversidade cultural indígena, europeia e africana, assim, precisamos valorizar cada cultura dando-lhes o devido lugar de destaque.

O domínio da escrita e a escravização fez com que as comunidades orais africanizadas perdessem suas histórias, ausentando-as no imaginário social das gerações mais jovens, por isso, tentamos resgatar, nesse breve estudo de relato de experiência, ressignificando as histórias de grupos que foram silenciados por vozes hegemônicas durante muitos séculos.

Pretendemos garantir o direito de voz aos invisibilizados socialmente e promover, por via oral, mais uma manifestação ativa que produza diálogo em intercessão de saberes e práticas entre Histórias, Cultura e Ciência.

Dialogamos, nesse trabalho, para que reflexões brotem das nossas memórias a fim de conhecermos um pouco mais sobre as histórias de muitos negros e negras que fizeram histórias, as quais precisam ser conhecidas na 
perspectiva da formação histórica e social, por meio de arte de contá-las e fazer ciência.

Sendo assim, dividimos o trabalho em três partes, no primeiro momento falaremos do início da disciplina ministrada no curso de Contação de Histórias, no qual abordamos assuntos referentes à diversidade dos contos e a importância de se trabalhar histórias europeias, indígenas e africanas para a valorização das diversas culturais.

No segundo momento falaremos dos textos africanos que foram desenvolvidos nas contações de histórias no curso, e podem ser dinamizadas para todo público em geral, inclusive na educação. E no terceiro tópico, apresentaremos os resultados da ministração do curso com a sua propositiva de abordar esse assunto num viés interdisciplinar com o ensino de ciências, bem como as reflexões sobre o fazer desses traços que se complementam na formação inicial e continuada.

\section{METODOLOGIA}

Este trabalho faz parte de um relato de experiência, ministrado em uma disciplina do curso de Formação Continuada de contação de Histórias no Instituto Federal de Educação, Ciência e Tecnologia do Rio de Janeiro(IFRJ), campus avançado de Mesquita, no município de Mesquita no Estado do Rio de Janeiro.

O eixo temático da disciplina foi "A contação de histórias por meio de textos afro-brasileiros e africanos, sendo que o eixo tecnológico do curso consistiu na Educação para o Ensino Fundamental, tendo uma carga horária de 8h semanais, a escolaridade mínima exigida para os cursistas foi do Ensino Médio incompleto. Quanto a periodicidade, as aulas aconteceram entre os meses de maio a outubro, sendo que as disciplinas ministradas descritas, neste artigo, aconteceram durante os meses de junho, julho e agosto de 2017 , no horário de $8 \mathrm{~h}$ às $17 \mathrm{~h}$, na modalidade presencial, no período diurno. 
As histórias africanas foram o foco de nosso estudo e dinamização, para que pudéssemos valorizar as contribuições dos africanos e afro-brasileiros nas contações de histórias, garantindo diversidade no trabalho, evidenciando os protagonistas negros que pensaram sua cultura e os fenômenos desse mundo sobre vários aspectos.

O público- alvo foi composto por, aproximadamente, 20 alunos, em que a grande maioria eram docentes, atuantes na Educação Infantil, etapa inicial da Educação Básica, alguns eram estudantes do Curso de Pedagogia, Letras e uma Professora de Biologia.

Dessa forma, realizamos contações e mediações de histórias, ora individualmente, ora de forma coletiva, refletimos sobre os contos, apresentamos e cantamos algumas músicas sobre a temática africana, sobre a leitura dos fenômenos naturais realizadas por elas, garantindo assim, novas abordagens e significações sobre a africanidade e Ciência.

A pesquisa teve a natureza exploratória, pois proporcionou maior familiaridade com os textos a serem trabalhados, seu planejamento foi flexível, proporcionando escolhas e seleções de novos materiais de leitura, suscitando várias reflexões sobre o fato estudado, assumindo a forma bibliográfica (GIL, 2002) a partir dos textos da Lei $10.639 / 03$, da Lei 11.645/08, do livro Textos e Pretextos sobre a Arte de Contar Histórias de Celso Sisto, do livro Alfabetização Científica questões e desafios para a educação, de Áttico Chassot, entre outros.

Os procedimentos técnicos utilizados para as leituras e estudos teóricos baseou-se num exercício bibliográfico de fontes impressas ou digitais, as quais constituem apoio nas reflexões sobre a temática estudada. Sendo assim, percorremos as etapas da pesquisa bibliográfica escolhendo o tema a ser investigado, organizando a leitura exploratória, seletiva e analítica para a redação escrita do texto.

A seguir, abordaremos alguns aspectos sobre a contação de histórias envolvendo a africanidade. 


\subsection{POR QUE CONTAR HISTÓRIAS AFRICANAS?}

Contamos histórias por sermos seres sociais, dinâmicos e ativos. Por sermos corpos históricos e elementos naturais. A todo o momento, os seres humanos estão envolvidos em contações de histórias, seja em ambientes formais de ensino ou em relações informações, as histórias estão sempre presentes e ajudam as pessoas a abrirem os olhos e o coração, e a compreenderem de forma fundamentada o mundo da ciência (SISTO, 2012).

A questão acima nos remete aos primórdios da humanidade, onde os saberes eram trabalhados nas reuniões familiares e comunitárias. Fatos como estes preservavam memórias, perpetuando culturas entre grupos de todo 0 mundo, preservaram historias e construíram ciência.

Com o processo de colonização, os grupos que utilizavam a tradição oral, no caso de grande parte dos africanos, foram aos poucos perdendo sua cultura oral, pois a nova cultura imposta ocultou quase toda a história dos povos escravizados, colocando no limbo histórias que explicavam riquezas do observar empírico.

Propostas com outras intenções, além das já apresentadas, foram colocadas em ação até que as gerações mais jovens fossem conduzidas a conheceram e , muito bem, os Contos de Fadas Clássicos europeus, escritos primeiramente, no século XVII, pelo francês Charles Perrault (1628-1703), coletados e escritos pelos alemães irmãos Grimm Jacob Ludwing Carl Grimm (1785-1863) e Wilhelm Carl Grimm (1786-1859) os quais entraram para a história como contadores de histórias a partir de suas pesquisas e buscas de contos populares que ouviam da comunidade alemã. Os irmãos Grimm apropriaram-se dos contos escritos por Charles Perrault dando um caráter alemão as histórias, tornando-as um pouco mais infantis, como Chapeuzinho Vermelho, A Bela Adormecida, A Gata Borralheira, entre outras.

O dinamarquês Hans Christian Andersen (1805-1875), também, foi um ícone na Literatura Infantil Mundial, autor de contos de Fadas como o Soldadinho de Chumbo, A Pequena Vendedora de Fósforos, A Princesa e o grão de 
Ervilha e tantos outros contos, deixou-nos como legado as mais belas histórias europeias, as quais estão presentes na formação cultural das gerações mais jovens e que nos remetem a sentimentos de profunda humanidade e alteridade com os sujeitos de uma sociedade.

Conhecer os escritos que o francês Charles Perrault contava nos salões de Paris e relacioná-las ao nosso universo cotidiano, como a história do Barba Azul, remete-nos à violência doméstica vivenciada por muitas mulheres brasileiras, tornando o texto tão atual quanto à época de sua elaboração escrita.

Dialogar com os irmãos Grimm sobre o caminho percorrido pela Chapeuzinho Vermelho até a casa da vovó é tão mágico e contemporâneo que nos faz reviver as muitas histórias dos percursos cotidianos, bem como os inúmeros lobos famintos que se encontram pelos caminhos.

As histórias registradas pelo dinamarquês Hans Christian Andersen, no século XIX, deixou-nos como herança, o duelo entre o feio e o bonito demonstrado na história do Patinho Feio, o forte e o Fraco apresentado na história da Pequena Vendedora de Fósforos, também, o dia 02 de abril, em que se comemora o "Dia Interacional do Livro Infanto-Juvenil" em homenagem ao nascimento do autor. As histórias enriqueceram de empatia, justiça e sensibilidade social os sujeitos ouvintes e leitores delas.

Diante desses dados, entendemos que, Charles Perrault no século XVII na França, os Irmãos Grimm Jacob Ludwing Carl Grimm e Wilhelm Carl Grimm na Alemanha, no século XVIII e Hans Christian Andersen, no século XIX na Dinamarca contribuíram para que os contos clássicos europeus chegassem ao Brasil por meio da colonização portuguesa, fazendo parte integrante de nossa formação escolar.

Voltando à questão inicial, e diante desse histórico, perguntamos novamente: Por quê contar histórias africanas? Como podemos articular as histórias africanas ao Ensino de Ciências? 
Com esses questionamentos, levantamos mais uma questão. Por quê ofereceu-se às gerações mais jovens uma única literatura, pautada em grandes autores de origem europeia? Na medida em que sabemos que somos resultados da interação de, pelo menos, três grupos culturais distintos que são os indígenas, os portugueses e africanos?

De forma democrática nos cabe buscar garantir a promoção da cultura diversa que fazemos parte e que as novas gerações conheçam, pelo menos, as contribuições dos povos que formaram nossa nação e assim ampliar àquilo que foi dedicado apenas a um grupo específico. Que a história não seja contada por um único e monocromático viés. Que ela corresponda a todos os elementos culturais, étnicos e sociais da formação de uma sociedade.

Estudar as histórias africanas faz parte de um trabalho de ressignificação de identidade Nacional, na medida em que, ao contarmos histórias de negros, permitimos visibilidade e acesso a diversas possibilidades literárias. Criamos alteridade acerca das culturas e etnias. A isso soma o que percebemos acerca das concepções de mundo e de fenômenos naturais que eram, exclusivamente, dedicadas ao olhar empírico.

Não temos a pretensão, nesse estudo, de supervalorizar a cultura africana, que nesse caso é o foco de nosso trabalho, e nem fazer uma historiografia do Ensino de Ciências, mas permitir que essas discussões também tenham espaço, assim como os contos clássicos mundiais, nas contações de histórias e na concepção formativa do ensino de ciências por meio dessas histórias que serão formativas de olhares e saberes acerca das realidades, acontecimentos e fenômenos naturais.

A Contação de histórias se constitui num movimento de divulgação e valorização das múltiplas histórias humanas que serão componentes importantes do imaginário social, que para Celso Sisto significa salvar o mundo imaginário (SISTO, 2012), visto que:

Com certeza, quem conta uma história tem clareza do que pretende atingir. Se o objetivo é apenas lúdico, se é 
discutir determinada ideia ou tema, se é despertar uma série de sentimentos e trazer informações, se é terapêuti$\mathrm{co}$, se pretende promover um aintegração social e cultural- para cada um há procedimentos e encaminhamentos diferentes, embora se saiba que quem conta um conto, aumenta um ponto, uma vírgula, uma exclamação e uma boca aberta diante da possibilidade de se construir um mundo melhor- povoado de histórias! (SISTO, 2012. Pg. 36)

Construir um mundo cheio de histórias é o que pretendemos, na medida que contar histórias é sempre um resgate de novas possibilidades e novos caminhos para a valorização humana, e é o que observaremos no relato de experiência, que tenta reconhecer a ancestralidade, a cultura que a permeia, que compõe e recompõe o cenário atual. A seguir, assinalamos, de forma resumida, o trabalho e a experiência por nós vividas, durante a ministração das aulas no curso de contação de histórias, bem como os diálogos que se estabeleceram a partir das mediações docentes em interações com os discentes.

\subsection{ODARA, VALENTINA E ABENA TRÊS PRINCESAS NEGRAS: AS EX- PERIÊNCIAS NO CURSO DE CONTAÇÃO DE HISTÓRIAS - CONTANDO O CONTO}

1-Stéphanie

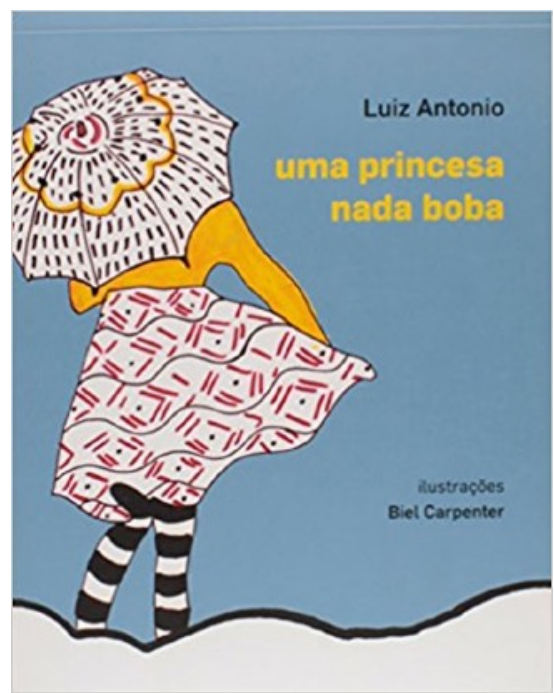

Fonte: Livro de Antonio Luiz 
Uma Princesa nada boba, de autoria de Luiz Antonio e ilustrações de Biel Carpenter foi uma história mediada durante as aulas no curso de Contação de Histórias. A história fala de Stéphanie uma menina negra que ainda não tinha descoberto sua identidade, vivia em busca de uma descoberta, enquanto isso se escondia atrás de uma sombrinha que ofuscava todos os desejos e ambições de ser uma princesa de verdade, pois ela percebia que não se adequava aos padrões estabelecidos para uma princesa.

A vó de Sthefanie desempenhou um papel fundamental no conto, resgatando a identidade da protagonista da história, levando a reconhecer a partir de um espelho mágico, muitas princesas africanas guerreiras e valentes.

Agora sim, Stéphanie, a verdadeira princesa Odara reconheceu sua identidade africana por meio de seus ancestrais. Stéphanie, de antes e a Odara atual, deixou a sombrinha que encobria seu rosto e caminhou de cabeça erguida mostrando com dignidade a princesa que realmente ela se tornou.

Contar a história da Princesa nada boba nos faz refletir sobre os padrões de beleza que são impostos culturalmente no imaginário social, fazendo com que os negros não se reconheçam como protagonistas de suas próprias histórias. Com a mediação desse texto, podemos trazer muitas princesas para o universo literário, valorizando assim, a cultura africana tão vasta e complexa. Concordamos com Celso Sisto (2012) quando ele diz que:

Se uma história, ainda que de forma velada e subliminar, ensina sempre, ela também ensina as questões étnicas e culturais, relevantes para quaisquer indivíduos. $E$ isso, nosso ofício de contadores pode e sabe executar bem. E nossas escolhas também devem ser criteriosas o suficiente, a ponto de ajudar a promovero respeito, principalemten, aos direitos humanso, ao meio ambiente e às questões de gênero (SISTO, 2012.p.11) 


\section{2-Odara}

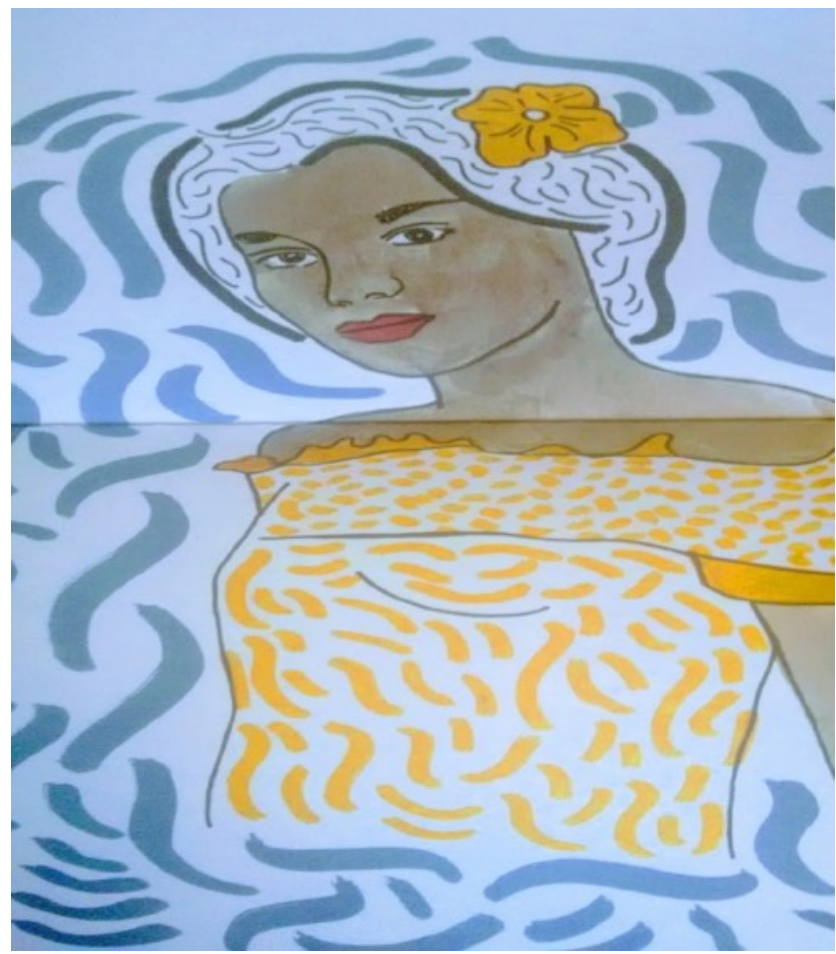

Fonte:Livro de Antonio Luiz

A outra história trabalhada no curso foi a "Valentina" úma princesa linda que, de acordo com o texto, mora na beira do bem longe. Princesa de bem longe, filha de pai branco e mãe negra, morando em uma comunidade nos morros cariocas, não deixa de se considerar uma princesa. Às vezes, Valentina não entende, muito bem, o motivo pelo qual tem de ficar com a tia o dia todo, para que seus pais, possam trabalhar para que ela possa ser alguém na vida. Ela não compreende muito bem, pois se sente uma princesa, dona de si e de suas escolhas. 
3-Valentina

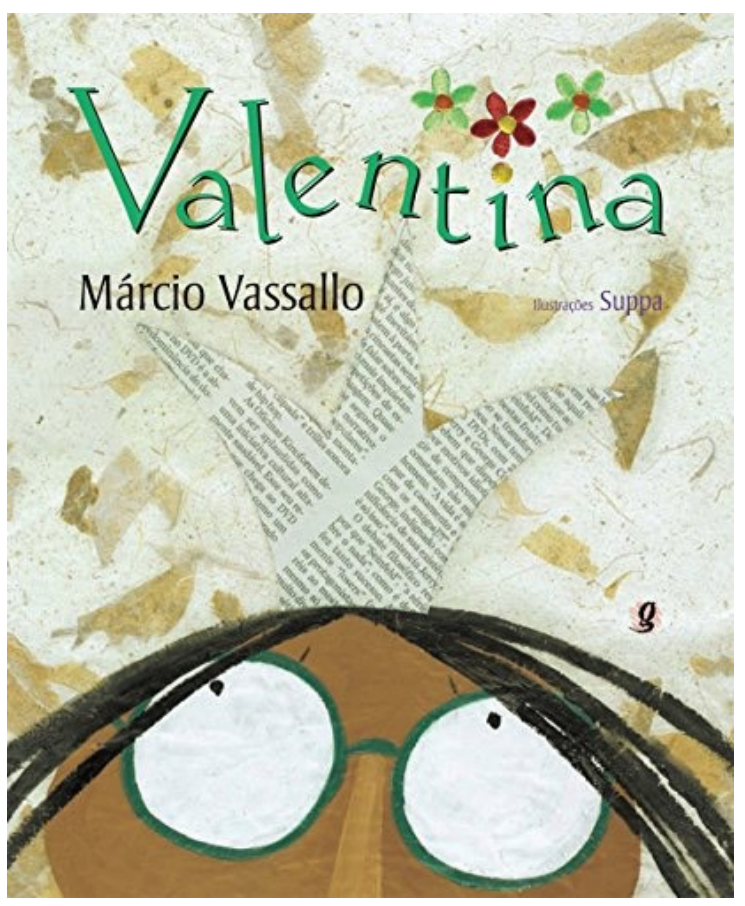

Fonte: Livro Valentina

Ao descer do morro para conhecer o "Tudo", Valentina não gosta do que vê, no "Tudo", pois todos procuram ser iguais e Valentina com simplicidade e inovação reafirma sua identidade, demonstrando força e resistência ao consumismo imposto pela cultura econômica!

Valentina percebe que a beira do bem longe ela tem tudo o que precisa para ser uma princesa de verdade, o carinho, cuidado, proteção e a dignidade de ser reconhecida como princesa. A história de Valentina faz uma ressignificação de nossos conceitos de Tudo e Nada. Ressignificando o perto do bem longe observamos que tudo está colorido e cheio de vida, enquanto no perto do "Tudo" o colorido é ofuscado pelo acinzentado universal do padrão único, do esterétipo, do modelo, do preconceito, da margem. Com Valentina, percebemos o quanto a felicidade imposta por um mundo que prioriza o capital nos engana com a felicidade representada na singeleza da vida da fantasia infantil. 
4-Localidade onde Valentina mora
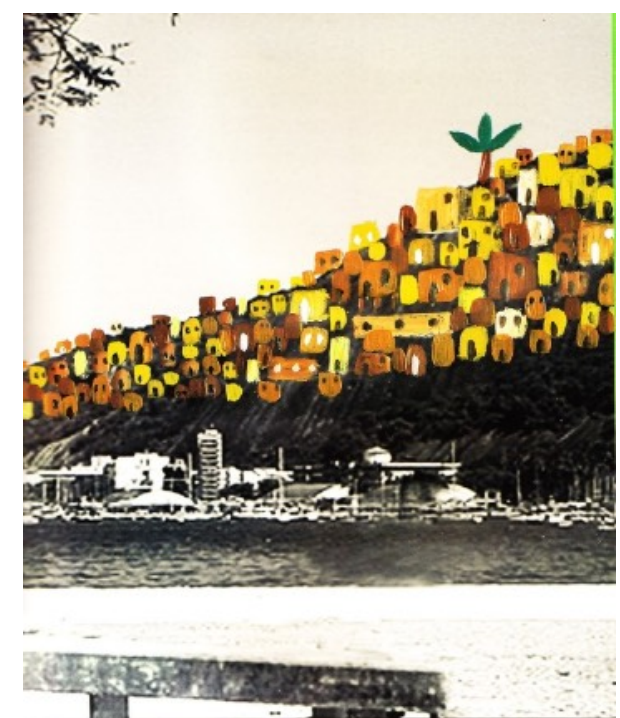

Fonte-Livro Valentina

Livro "O casamento da princesa" de Celso Sisto e ilustrações de Simone Matias é um reconto da África Ocidental com personagens típicos da região e culturas próprias em que Abena, a princesa mais linda do mundo é disputada por dois pretendentes que são a Chuva e o Fogo, ambos elementos primordiais para a aldeia onde Abena vive. Contamos a história para os alunos do curso e depois realizamos debates sobre os diversos diálogos possíveis elencados por meio do texto.

\section{5-Abena}

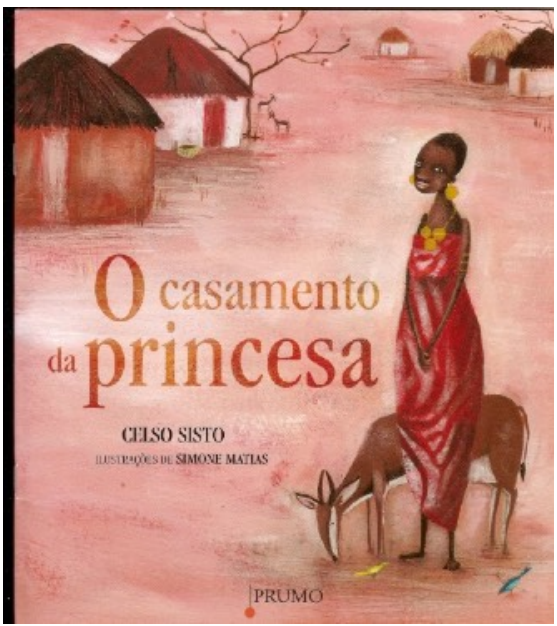

Fonte: Livro o casamento da Princesa 
Ressaltamos a imagem de Abena, a protagonista da história, a qual quebra muitos paradigmas culturais de princesas europeias, pois a princesa é apresentada usando trajes suntuosos, demonstrados nas imagens que Simone Matias ilustrou com maestria. Abena é a princesa mais linda do mundo, possui seios grandes, rosto arredondado e pescoço alongado e com a notícia da suprema beleza, muitos pretendentes correm para vê-la e pedi-la em casamento.

Chuva e Fogo são os primeiros pretendentes. O Fogo conversou diretamente com o rei, pai de Abena, prometendo mundos e fundos a sua futura esposa, garantindo ser um parceiro ideal para aquecer e prover o necessário para o bem estar da princesa.

No mesmo instante que o Fogo acertava os detalhes do casamento com o Rei, A Chuva sem saber da presença do Fogo, chuviscava todo encanto nos ouvidos de Abena, que imediatamente ficou enamorada com os dotes da Chuva, dizendo que "até as savanas de Burkina Fasso, até as areias do Golfo da Guiné, plantações do Togo, até as florestas da Costa do Marfim, não existiria ninguém mais poderoso que ela". (SISTO, 2009.p.10)

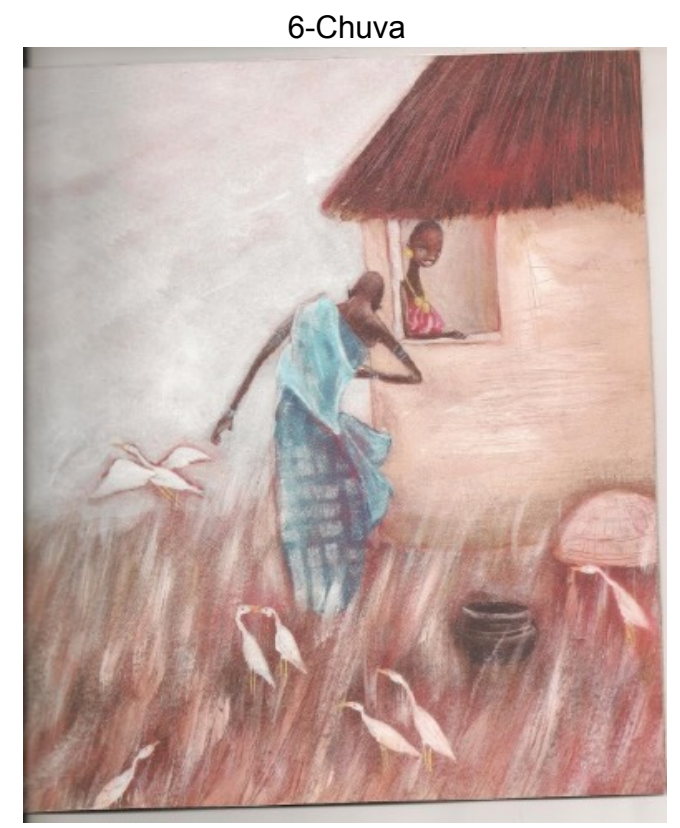

Fonte: Livro casamento da princesa 
As palavras da Chuva fizeram rolar o amor no coração de Abena que logo disse para o pretendente ir no outro dia acertar os detalhes com o rei.

No outro dia, os dois pretendentes tiveram que apostar uma corrida para saberem quem seria o vencedor e este casaria com Abena. O rei deu a partida e o na linha de chegada quando o Fogo já era quase o vencedor, a Chuva caiu, num aguaceiro do tamanho do mundo e o fogo que corria destemido apagou com a força da Chuva.

Abena que sabia desde o início quem deveria estar do seu lado, correu nos braços da Chuva e bailou uma linda canção, comemorando seu casamento com a chuva.

Com a História do casamento da princesa muitas reflexões e diálogos se estabeleceram ente os participantes do curso como: o papel da mulher negra na sociedade, a beleza, estética e trabalho negro, além das questões de cabelo, corpo negro e construção da identidade.

\subsection{CANTANDO TAMBÉM CONTAMOS HISTÓRIAS.}

\section{O QUE VEM À NOSSA CABEÇA QUANDO FALAMOS A PALAVRA "ÁFRICA"?}

O questionamento acima foi feito no início de uma das aulas do curso para abertura de debates e discussões sobre o Continente Africano, suscitando muitas indagações e representações sociais sobre o imaginário construído em relação ao Continente.

As respostas dadas pelos alunos do curso, foram contempladas com as seguintes palavras: miséria, fome, savana, pobreza, colorido, animais selvagens, escravidão, alegria, religiões e tantas outras coisas foram ditas que apontaram fragilidades e limites trabalhados em nível de territorialidade, cultura e Ciência. 
Após o debate, apresentarmos a música "África", do Cd da Palavra cantada para ampliarmos os saberes sobre o Continente Africano, espaço múltiplo de culturas e inúmeras diversidades.

Africa

Palavra Cantada

Quem não sabe onde é o Sudão

saberá

A Nigéria o Gabão

Ruanda

Quem não sabe onde fica o Senegal,

A Tanzânia e a Namíbia,

Guiné Bissau?

Todo o povo do Japão

Saberá

De onde veio o

Leão de Judá

Alemanha e Canadá

Saberão

Toda a gente da Bahia

sabe já

De onde vem a melodia

Do ijexá

o sol nasce todo dia

Vem de lá

Entre o Oriente e ocidente

Onde fica?

Qual a origem de gente?

Onde fica?

África fica no meio do mapa do mundo do

atlas da vida

Áfricas ficam na África que fica lá e aqui

África ficará

Basta atravessar o mar

pra chegar

Onde cresce o Baobá

pra saber

Da floresta de Oxalá

E malê

Do deserto de alah

Do ilêBanto mulçumanamagô

Yorubá

(CD Palavra Cantada de Paulo Tatit e Edith Derdyk) 
Com essa música, não somente contamos histórias sobre o Continente Africano, mas também, trouxemos ao diálogo conhecimentos, linguagens culturais que nos foram ocultadas, por um longo período de tempo, pois:

Se estamos, portanto, diante de uma relação entre quem promove a vivência (professor) e quem vivencia (o aluno), estamos também imersos numa relação de ensino-aprendizagem. Para os tempos atuais, estamos diante da possibilidade de fazer do ato de narrar uma história, um exercício de inclusão, porque impotante para toda e qualquer idade[...](SISTO, 2012.Pg. 11)

Olê, lê

Olê, lê

Molibá, makasi

Oboing bambá

Molibá Makasi

(https://www.youtube.com/watch?v=h7MYdSUVm2Y)

Concluímos, com essa história cantada na língua lingana, do País de Gana, que significa que precisamos remar sempre, a correnteza está forte, mas precisamos remar. Precisamos conhecer, partilhar saber, entender ciência e viver cultura sem preconceitos.

Por fim, dialogamos que tais historias entremeadas com a vida, segundo Chassot (2006), é o que falta ao entendimento da Ciência. Há que ser superado o caráter meramente produtivo do conhecimento, por isso, segundo o autor, há que se delinear a interpretação da ciência como uma produção cultural e de forma a incluir as ciências nos vários aspectos da vida, e por que não na Contação de histórias?

\section{REFLEXÕES E RESULTADOS SOBRE OS CONTOS: CAMPO E AÇÃO}

Ao apresentarmos as histórias aos alunos do curso de Contação, selecionamos os três textos onde as protagonistas são mulheres, princesas e negras, figuras importantes que serviram para ressignificar nossas concepções de felicidade, de beleza, de princesas, de visões de mundo estabelecidas social- 
mente. Esse fato nos levou a pensar a construção social em torno de gênero, visão cultural, designação histórica e Ensino de Ciências para o Ensino Fundamental.

Utilizamos alguns aspectos legais para fundamentar nossas ações, como a Lei 10.639 de 09 de janeiro de 2003 que alterou a Lei no 9.394, de 20 de dezembro de 1996, pois estabelece as diretrizes e bases da educação nacional, para incluir no currículo oficial da Rede de Ensino a obrigatoriedade da temática "História e Cultura Afro-Brasileira, dizendo que nos estabelecimentos de ensino fundamental e médio, oficiais e particulares, torna-se obrigatório o ensino sobre História e Cultura Afro-Brasileira (BRASIL, 2003).

Aprofundamos, nosso estudo, também, na Lei 11.645 de 08 de março de 2008 onde se alterou a Lei no 9.394, de 20 de dezembro de 1996, modificada pela Lei no 10.639, de 9 de janeiro de 2003, que estabelece as diretrizes e bases da educação nacional, para incluir no currículo oficial da rede de ensino a obrigatoriedade da temática "História e Cultura Afro-Brasileira e Indígena, dizendo que nos estabelecimentos de ensino fundamental e de ensino médio, públicos e privados, torna-se obrigatório o estudo da história e cultura afrobrasileira e indígena.(BRASIL, 2008)

Sendo assim, compartilhamos com os alunos do curso o que diz respeito as lutas e conquistas dos movimentos sociais de inclusão, bem como as leis que garantem a obrigatoriedade de temas africanos, afro-brasileiros e indígenas no currículo da Educação Básica.

Estudamos e dialogamos com os alunos, aspectos relacionados ao Fogo e Chuva como elementos importantes para a sobrevivência humana, bem como, a descoberta do Fogo. As propriedades, utilidades e importância da água para a humanidade são aspectos que foram explorados a partir da literatura de Celso Sisto, articulado ao Ensino de Ciências numa proposta interdisciplinar.

Com Stephanie, a personagem do livro "Uma princesa nada boba" de autoria de Luiz Antonio, observamos e discutimos o quanto foi difícil para ela se 
auto afirmar como princesa, num contexto de não reconhecimento de si, diante dos modelos estabelecidos, com os quais ela não fazia parte.

Com isso, muitas alunas se identificaram com a personagem, e sinalizaram que em algum momento de suas vidas agiram como a personagem da história, escondendo-se, na maioria das vezes por conta de estereótipos pré- estabelecidos.

A presença da avó foi o elo de ressurgimento e formação da identidade, para que Odara, agora a nova personagem do livro, deixasse de se esconder e mostrasse, com coragem, a princesa que realmente ela havia se tornado. Um registro de formação de identidade negra acontece no transcurso da história.

Com a história de Valentina, de autoria de Márcio Vassalo e ilustrações de Suppa, aprendemos, em interação coletiva,que apesar dos lados antagônicos e injustos, a simplicidade, a força e a ousadia da princesa reforçada nas imagens, permitiu-nos um novo olhar para os moradores de comunidades cariocas, da territorialidade e dos aspectos socioambientais que permeiam esse cenário.

Com Abena no livro de Celso Sisto "O casamento da princesa" e ilustrações de Simone Martins, quebramos mais uma vez os paradigmas de gênero, beleza e eurocentrismo. Há uma crítica, não velada, às questões que segmentam e hierarquizam cultura e pessoal. Tal fato é demonstrativo de uma preocupação que envolve processos de humanizações no ensino informal e na Contação comprometida com reflexões, a partir de contextos de exclusão e preconceitos.

Ainda que Abena seja a princesa mais linda do mundo, desenhada e retratada com a beleza singular, a coragem de dizer para si mesma que só iria se casar com a Chuva, o seu pretendente favorito e amado é o dado maior. Nessa história,natureza e humanidade se entrelaçam para que Contação e Ciência sejam trabalhadas na mesma dimensão, e é nessa seara que nos aventuramos. 
Esses três textos nos conduziram a reflexões importantes sobre as figuras de princesas que fizeram parte de nossas histórias, e que, na maioria das vezes, eram princesas participantes do perto do "Tudo", onde os modelos e os padrões deveriam perpetuar por gerações, apresentando um único modelo a ser transmitido. Questionamos modelos, formas lineares e indutoras e assim, colocamos em foco discussões tomadas por contextos interdisciplinares na Contação.

Odara, Valentina e Abena são clássicos da literatura contemporânea, princesas únicas, simples, corajosas e acima de tudo valentes, capazes de protagonizar histórias que coloquem em questão modelos de beleza, preconceitos raciais e de gênero, senso comum, mitologia, ciência e musicalidade.

\section{CONSIDERAÇÕES}

O trabalho desenvolvido em aula, durante as ministrações num curso de Formação Continuada de Contação de Histórias no Instituto Federal de Educação, Ciência e Tecnologia do Rio de Janeiro, no campus avançado de Mesquita, Estado do Rio de Janeiro, buscou revisitar a discussão sobre a relação entre ciência, saberes africanos e afro-brasileiros na Contação de Histórias e que nos levaram à compreensão das diferenças culturais, sociais e ambientais no universo de ensino fundamental, despertando para a existência formadora de diferentes culturas no plano da sociedade.

Contar histórias é um movimento de resgate, de buscas de inserção na realidade a fim de trazer para o campo coletivo o debate sobre os preconceitos, racismos e estereótipos que são construídos socialmente, e que perpetuam nos contos, nos discursos cotidianos, nas ações e práticas de sala de aula.

Diante isso, a ação de contar e compartilhar histórias, neste trabalho, envolvendo a África, afro-brasileiros e o ensino de Ciências contribuiu para que novos discursos fossem dinamizados num fazer coletivo envolvendo ações reflexivas. 
Estudar a origem dos contos clássicos europeus, situar no universo das Leis $10.639 / 03$ e 11.645/08 foi fundamental para entendermos o quanto precisamos lutar pela valorização das culturas africanas, afro-brasileira e indígena, garantindo que muitas sujeitos tenham visibilidade e a valorização das diversas etnias que colaboraram para a formação cidadã e crítica.

Conhecer histórias de princesas africanas e afro-brasileiras como Abena, Odara e Valentina é um caminho de quebra de estereótipos de uma sociedade eurocêntrica, branca e racista, onde os padrões são disseminados como um único, em detrimento de outros, por isso, a importância de garantir novas possibilidades para a diversidade.

Apreendemos que podemos contar histórias de diversas maneiras para públicos diferentes, e foi o que aconteceu no curso de contação de histórias. Estudamos, cantamos, contamos e compartilhamos muitas e muitas histórias a fim de promovermos reflexões sobre ações coletivas e interdisciplinares, interagirando com diversas vozes e linguagens, inclusive com as ciências naturais, pois essa está em nós no que somos e no que nos formamos.

\section{REFERÊNCIAS:}

ANTONIO. Luiz. Uma princesa nada boba. São Paulo: Cosac Naify, 2011.

África, palavra cantada. Disponível em: https://www.letras.mus.br/palavra-cantada/ $\underline{9789321}$

Acesso em 15/12/2017 às 5 h e 37 min.

As características da cultura tradicional africana, suas múltiplas facetas, a oralidade, mitologia, religiosidade e formas de expressão In: Introdução à Cultura Africana. Lisboa: Edições 70, 1977. Disponível em: https://cadernodematerias.files.wordpress.com/2012/03/a-tradic3a7c3a3o-viva-amadou-hampatc3aa-bc3a1.pdf

BRENAMN, Ilan. Através da vidraça da escola: formando novos leitores/ Ilan Brenamn 2.ed.-Belo Horizonte:Aletria, 2012.

BRASIL. Lei de Diretrizes e Bases da Educação Nacional. Lei número 9394, 20 de dezembro de 1996. Lei de $\mathrm{n}^{0} 10.63909$ de janeiro de 2003. Lei de $\mathrm{n}^{\circ} 11.645$ de 08 de março de 2008. 
CHASSOT, Attico. Alfabetização científica: questões e desafios para a educação. ljuí: Unijuí, $1^{\text {a }}$ ed. 2006, 434 p., $2^{\text {a }}$ ed. 2006, 438 p.

FRAZÃO, Dilva. Charles Perrault. Disponível em: https://www.ebiografia.com/ charles_perrault/ 03/11/2017 às $14 \mathrm{~h}$ e $26 \mathrm{~min}$

Dilva, Irmãos Grimm, Folcloristas alemães Disponível em: https://www.ebiografia.com/irmaos_grimm/ dia 03/11/2017 às 14h e39min

http://eraumavezuem.blogspot.com.br/2012/10/valentina-princesa-da-beira-dolonge.html. Acesso em: 03/11/2017 às $21 \mathrm{~h}$ e $18 \mathrm{~min}$

Ole, le, ole,le moliba makasi. Disponível em: https://www.youtube.com/watch? $\mathrm{v}=\mathrm{h} 7 \mathrm{MYdSUVm} 2 \mathrm{Y}$. Acesso em 15/12/17.5h e $30 \mathrm{~min}$

SISTO, Celso. O casamento da princesa. São Paulo; Prumo, 2009.

Celso. Textos e Pretextos sobre a arte de contar histórias. 3.ed.rev. e ampl. - Belo Horizonte: Aletria, 2012.

VASSALO, Marcio.Valentina. São Paulo: Global, 2007. 